\title{
LA ACTUALIDAD DE LUIS EDUARDO NIETO ARTETA
}

Emilio Echeverri Mejía*

\section{Anfora}

racias al temerario designio de nuestro común amigo, hijo ilustre de esta amable tierra, el doctor Otto Morales Benítez, y de César Valencia Trejos, he venido a acompañarlos en este el XII Encuentro de la Palabra, que con regularidad encomiable reúne anualmente a aquellos artífices del arte de expresar, en poesía, en prosa, en discurso, en balada, el mejor testimonio de su existencia, hecho con el rigor de la forma, con la exigencia del estilo, propio de los artesanos de la lengua, que son todos los de estas tierras y que interesan la mente del prójimo.

Se me señaló como tema, en gesto generoso y que aprecio, porque estaba dirigido a facilitarme el que pudiere yo decir algo, en un evento para el cual en estricta justicia, sólo debiera oír, el que refiriera algo sobre mi experiencia en café.

Quién lo creyera! Más de 25 años en contacto directo, de vida -y porque no decirlo- inclusive grata dependencia de la amable rubiácea, no son suficientes para que una sola existencia logre acumular en café experiencias tan singulares que bien puedan merecer el ser relatadas y menos en actos como el presente.

He encontrado más útil y adecuado a las circunstancias, el apelar al testimonio ajeno. 
En concreto, pienso que bien sería útil que trajéramos el testimonio de alguien, que habiendo observado el café como una instancia intelectual y que a pesar de haber sido colombiano, ni nació en él, ni lo cultivó, ni lo trasegó, ni lo cosechó, ni menos lo devengó, le hizo al café el impagable homenaje de escribir su mejor biografia, resaltando su condición heróica como el más importante actor de la historia económica, política y social de Colombia, desde mediados del siglo pasado.

Se trata de Luis Eduardo Nieto Arteta. La primera sorpresa sobre nuestro testigo es la de saber que. nació y murió en Barranquilla en 1956, luego de haber vivido escasos 43 años.

Hoy se le podía clasificar, en la rara especie de los sociólogos jóvenes, condición más evidente cuando a los 35 años escribió el ensayo que hoy nos ocupa: «El Café en la Sociedad Colombiana».

He creído importante recordar hoy a Nieto Arteta, como un homenaje a una forma escasa, especialmente en estos días, del ejercicio intelectual en Colombia: el de dirigir la mirada y usar la mente para escudriñar aquellos valores, aquellos fenómenos, que han hecho posible la construcción de lo que aún queda del país.
Los que ahora vivimos, asistimos a un esfuerzo colectivo por negar, por destruir lo que somos y lo que en arduo y paciente transcurso de la historia, aún joven, hemos construido, como base de la estabilidad nacional.

En esa ferocidad destructiva, para la cual muchos se valen del ilustrado título de economistas del café, les sirve la rubiácea como el mayor y mejor objetivo. Se le quiere desconocer. Se le quiere desaparecer como planta maldita, con la ilusión de que su fin sería el comienzo de una etapa económica más promisoria para los colombianos.

Como está dicho, a mi juicio, el mérito de Nieto Arteta es el de descubrir la importancia del todo en una de sus partes: la misma técnica de aquellos humanistas aleccionadores sobre el arte que bien vislumbran cualquier obra maestra en la majestuosidad de los detalles.

Se podría decir que Nieto Arteta, sin que él lo escriba, para descubrir el café en Colombia, parte del mismo pensamiento que se le atribuyera a Antonio José Restrepo cuando identificaba y definía a Colombia como café. «Colombia es café y no es», decía en frase que, aún tiene validez.

Para Nieto Arteta, «las condiciones internas y externas han propiciado 


\section{- Los que ahora vivimos, asistimos a un esfuerzo colectivo por}

negar, por destruir lo que somos y lo que en arduo y paciente transcurso de la historia, aun joven, hemos construido, como base de la estabilidad nacional.9

la hegemonía de que disfruta el cultivo del café en Colombia». Así empieza su obra.

Las condiciones internas son la geografía de un país de la franja ecuatorial con 6 vertientes principales, propias de las 3 cordilleras que cruzan el territorio colombiano de sur a norte.

En los costillares de dichas cordilleras, Colombia tenía el suelo y el clima para una planta ajena a nuestro Continente, que abrió un espacio nuevo para la actividad económica de la creciente población del período republicano, que encontró allí un suelo para una actividad económica independiente, base de nuestra fortaleza democrática. Tierra que a su vez. acogió el café como la planta precisa para una explotación económica valedera.

Recuerda Nieto cómo en el siglo pasado, después de la independencia, nuestra historia se caracteriza por la gran inestabilidad política. Las guerras civiles, el permanente cambio de constitución en medio de las balas y la retórica, tuvo su origen en la falta de un producto de exportación estable.

La fugaz aparición y muerte del tabaco en la década de 1850 y 60 , del añil en los 70 y la quina en los 80 , fueron fogonazos de una incipiente actividad, efímera. contingente, de muy pobre representación en el comercio exterior y por sobre todo. de espasmódica existencia.

Aunque el café se sembró en Colombia en los primeros años de la independencia, su mejor auge lo tuvo después de 1875, habiéndose mantenido hasta nuestros días como una actividad permanente. que ha resistido crisis profundas, como la que ahora sobrevivimos, pero sin que haya desaparecido o se haya interrumpido desde entonces como fuente de ingreso y empleo para la vasta población que lo trabaja.

Para Nieto Arteta, este hecho ha dado el mayor beneficio a Colombia: LA ESTABILIDAD. Estabilidad en la economía que encontró un hilo 
continuo conductor de divisas. Estabilidad política especialmente después de la guerra de los mil días, causada en buena parte por la gran crisis del café de fin del siglo pasado. Estabilidad en el desarrollo regional de una economia de archipiélagos en la Colonia, con vastas zonas de latifundio de tierra fría en el lomo de las cordilleras y dispersos filones de metales que inducian a una explotación secundaria. Estabilidad política además, fundada en la gran revolución que significó el que una inmensa población pudiera colonizar las tierras vacías de las laderas montañosas y emprender una actividad rentable, de exportación, adicional al siempre e incipiente pan coger. Estabilidad para un país que pudo integrarse gracias a los medios de transporte inspirados por la vocación de exportación propia del café. Estabilidad para la democracia que encuentra su mejor fortaleza en los votantes que tienen algo que defender, distinto a los favores del Estado.

No vacila Nieto Arteta en señalar el café como el agente de la maduración política e institucional de Colombia, al permitir el goce rentable de la tierra a un sinnúmero de pequeños propietarios cafeteros, fenómeno inconcebible dentro de las opciones agrícolas alternativas, especialmente en el siglo pasado y los primeros 70 años del presente.

Para Nieto, el café cambió inclusive el perfil de los gobernantes colombianos. El financista, el práctico de origen cafetero, sustituyó al retórico, al irrumpir en el escenario del país gentes con una visión sobre el progreso y el sentido de la empresa, como misión primordial del ejercicio público, aparte de haber dado dimensión y continuidad al comer-

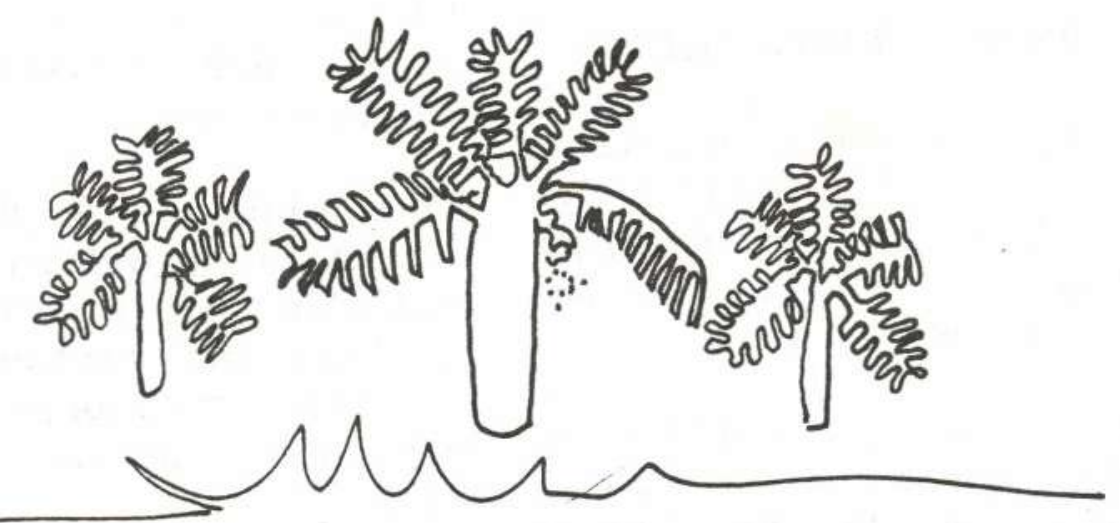

Universidad Autónoma 83 
cio internacional, gracias al fomento continuo e ininterrumpido de las divisas generado por éste.

Para Nieto Arteta, uno de los hitos de progreso institucional de Colombia, muy ligado al café, lo constituyó la fundación de la Federación Nacional de Cafeteros en 1927, la entidad encargada de defender a los cultivadores, especialmente en la comercialización, resaltando la vinculación del Estado con ésta, al entregarle, mediante contrato, la protección de la industria.

Más sorprendente aún en la óptica de Nieto, es la celebración del acuerdo de cuotas para conjurar la crisis de 1940 y la creación del Fondo Nacional del Café. Para Nieto Arteta, este paso significa la racionalización de la industria. propia del espíritu práctico y propio de quienes les corresponde forjarse su propia ventura.

\section{VIGENCIA DE NIETO ARTETA}

46 años después de escrito el libro que nos ocupa «El Café en la Economía Colombiana», bien vale la pena indagar sobre la vigencia de sus conclusiones.

Aparte del peso que el café tiene en la economía colombiana, especialmente en la de quince departamentos del país, no dudo en afirmar que su efecto estabilizador sigue vigente.

Las zonas cafeteras son las menos vulnerables al persistente esfuerzo de subversión. Esta sólo encuentra presencia, con poder, en las vastas áreas vacías del país, como lo fueron nuestras cordilleras hasta fin del siglo pasado y principios de éste.

Lo demás ha sido el choque de quienes quieren hacer la revolución contra los que ya la hicieron y disfrutan hoy lo que es el premio de las promesas de ésta: LA LIBERTAD fundada en la participación directa en un medio de producción. En nuestro caso, simplemente una combinación prividencial para Colombia: LA TIERRA MAS EL CAFE.

Mientras los trescientos mil cafeteros que pueblan las vertientes de Colombia puedan mantener una vida digna, la estabilidad, la propia del café y gracias a éste, seguirá representando una esperanza de paz para el país.

No se vislumbra ya en finales del siglo $\mathrm{XX}$, una actividad que en Colombia ofrezca mayor oportunidad económica para tantos. Su defensa sigue siendo una labor patriótica de bien que debe comprometernos a todos.

* Ponencia presentanda en el XII Encuentro de La Palabra. Riosucio (Caldas). 